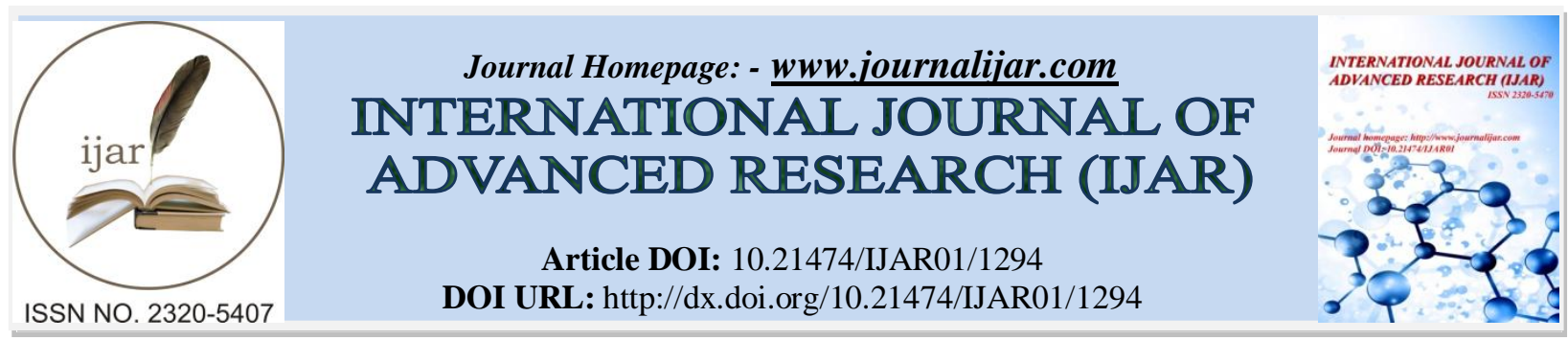

RESEARCH ARTICLE

\title{
DEVELOPMENT OF A COMPATIBILITY MODEL FOR INFORMATION SYSTEMS BASED ON TOTAL QUALITY MANAGEMENT.
}

\begin{abstract}
Abdulkhalek M. Kadir.
Erbil Technical Engineering College, Erbil Polytechnic University-Iraq.
\end{abstract}

\section{Manuscript Info}

Manuscript History

Received: 12 June 2016

Final Accepted: 22 July 2016

Published: August 2016

Key words:-

Total quality management TQM, Information systems IS, elements of TQM, maintainability attributes of IS, Compatibility model, quality level.

\begin{abstract}
Total quality management "TQM" is an arranged system of quality, it deals with requirements of customers and uses strategy to integrate quality discipline with other activities, it strives to provide customers with required products and services in any organization. "TQM" has eight elements in order to enhance quality level and avoid defects in other systems such as information system "IS". Here, the "IS" is an organizational arrangement of information and depends on four maintainability attributes of how such system stores, processes, manages and makes information available for use by both software and hardware systems. Four maintainability attributes of "IS" can be inserted into eight elements of "TQM" and make integration between their tasks to develop a model of compatibility in an organization, because the compatibility is a state in which two functioning systems are able to unify their tasks such as "TQM" and "IS" in one integrated system, constituting a model of compatibility. Here, this model comprises of four compound elements and several procedures. Many studies affirmed that inserting quality system into other systems leads to better control and services by $86 \%$ and $73 \%$ respectively which return as advantages to our study here, and to improve "IS" outcomes as well.

As a new topic, the compatibility is regarded as a new model to increase stability, repair, restoring, and quality level of "IS" outcomes. As a new tactic, the compatibility procedures are come by the way of integrating and inserting four main attributes of maintainability of "IS" into eight key elements of "TQM".
\end{abstract}

Copy Right, IJAR, 2016,. All rights reserved.

\section{Introduction and literature review:-}

Total quality management "TQM" is an arranged system of quality in an organization, it is a management system deals with customer requirements and uses strategy to integrate quality discipline into other activities [1], in all cases, there are three degrees of quality: (1) good, (2) better, and (3) best, they are used to suggest different ways in which management may secure and maintain information systems of organizations [2].

Information System "IS" is a study of how such system store, process, manage and make information available for use, and it depends on some maintainability attributes. The "IS" was defined by many researchers worldwide, most 
of them stated that "IS" is the process that collects, processes, stores, analyzes, and disseminates information for a specific purpose, it is used to acquire, store, manipulate, manage, display, transmit, deliver, and receive data by a group of interrelated components of hardware, software data, procedures, and people [3], others gave more details, they defined "IS" as: the complementary networks of hardware and software that the people and organizations use them to collect, filter, process, make, and distribute data, in order to produce an information system from hardware, software, data, procedures, user, and feedback [4\&5].

The compatibility can be done between quality and information system in order to give more advantages to related organization, it is a state in which two systems able to integrate their processes or some of their components can work together [6].

As literature review, there were several previous studies as follows:

- About elements of "TQM", several studies were specified 5-8 elements of "TQM" in order to establish a quality system, and regarded them as applicable elements in any operation, such as: ethics, integrity, trust, training, teamwork, leadership, recognition, and communication, but other scientists added customer focus and employee involvement as well [7].

- About attributes of maintainability, many studies were agreed that there are 4 main attributes of maintainability of "IS" such as: clearly control, dependability, user contribution, and training [8].

- About statistical relationship, a study found that there is statistical relationship between all elements of the "TQM" with level of software quality, these findings came out after the researcher has distributed questionnaire to 100 directors working in developing software quality [9].

- Other studies were tried to complete the interrelation between "TQM" and "IS", but they used other ways, one of them aimed to protect information from unauthorized employees and explained how "TQM" model could aid to improve "IS" deficiencies, other research was applied the method of enhanced "TQM" construct with triple bottom line TBL on the basis of relevance lack, limited access, absence of training, and poor security LLAP [10].

\section{Data collection and methodology:- Elements of TQM:-}

"TQM" is a management approach that strives to provide customers with products and services which satisfy their needs and enhances quality level, it tries also, to avoid wastes and defects in any operations [11], also as business, it looks at the products and services of a company in order to obtain complete customer satisfaction services [12]. A study was mentioned 7 key elements of "TQM" such as: management commitment \& leadership, teamwork, training and education, communication, customer focus, employees' participation, and culture [13], but other studies specified more than this limit, they mentioned between 6 to 8 key elements in order to build more successful implementation of "TQM" [10\&7], therefore, as mentioned above in literature review, to gain best results, the organization should focus on 8 elements of "TQM" of ethics, integrity, trust, training, teamwork, leadership, recognition, and communication, as they are indicated in figure (1).

Quality system will give many benefits, the European Community EC research with Lloyd's research, concluded that quality system gives more internal benefits when implemented with higher percentage such as: improved perception of quality significance (16\%), clearer duties of the employees (11\%), better employee job involvement $(9 \%)$, also they claimed that quality system formed those conditions for each of: better management control to (86\%), supply a better service for the customer to (73\%), increased effectiveness to (69\%), decreased costs to (40\%) and increased employee motivation to (50\%) [14]. 


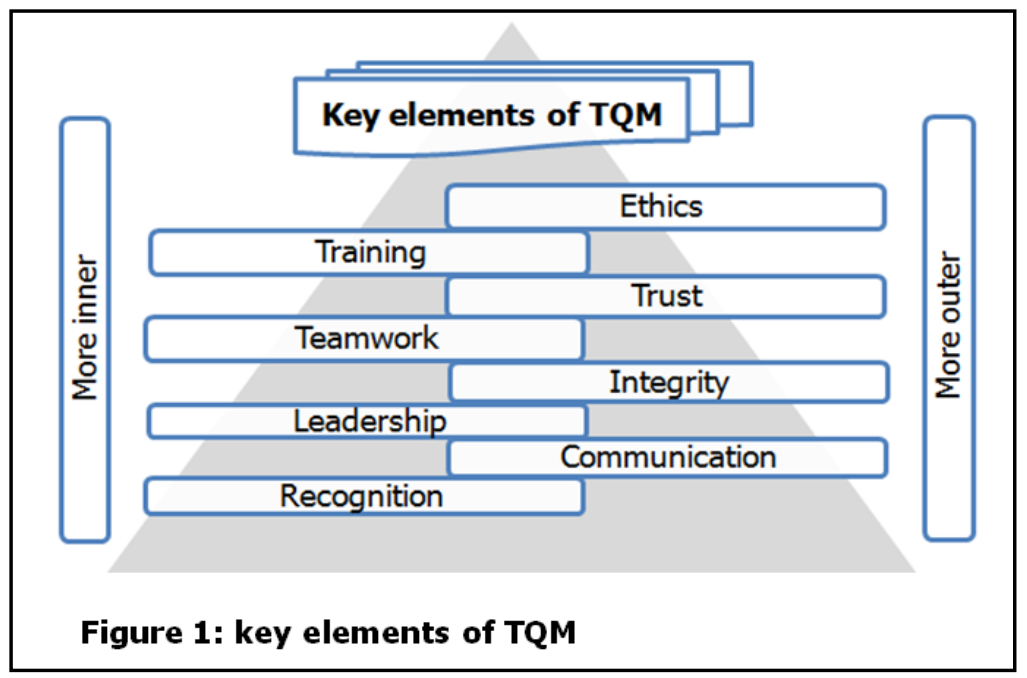

\section{Information system IS:-}

Information system "IS" means design of information and represents how it will be implemented in an organization, according to British Computer Society BCS, the information system "IS" is not computer science or software engineering, but it assists organizations to design and implement information and prepare technologies that support them [15].

"IS" has a wide range of working; therefore, it holds several titles and many meanings [15] as indicated in table (1). "IS" can give more accurate results, because in its processing, it takes both technical and behavioral features associated with design and outcomes in which comprises communication and information technology, "IS" assumed as a study of how such system stores, processes, manages, and makes information available for use by both software systems and hardware systems, therefore there are various types of "IS" in any organization [16] as indicated in table (1). But in general, "IS" is a system composed of people and computers that process information as an academic study with a specific reference to information and complementary networks of hardware and software in order to collect, filter, process, make, and distribute data [17].

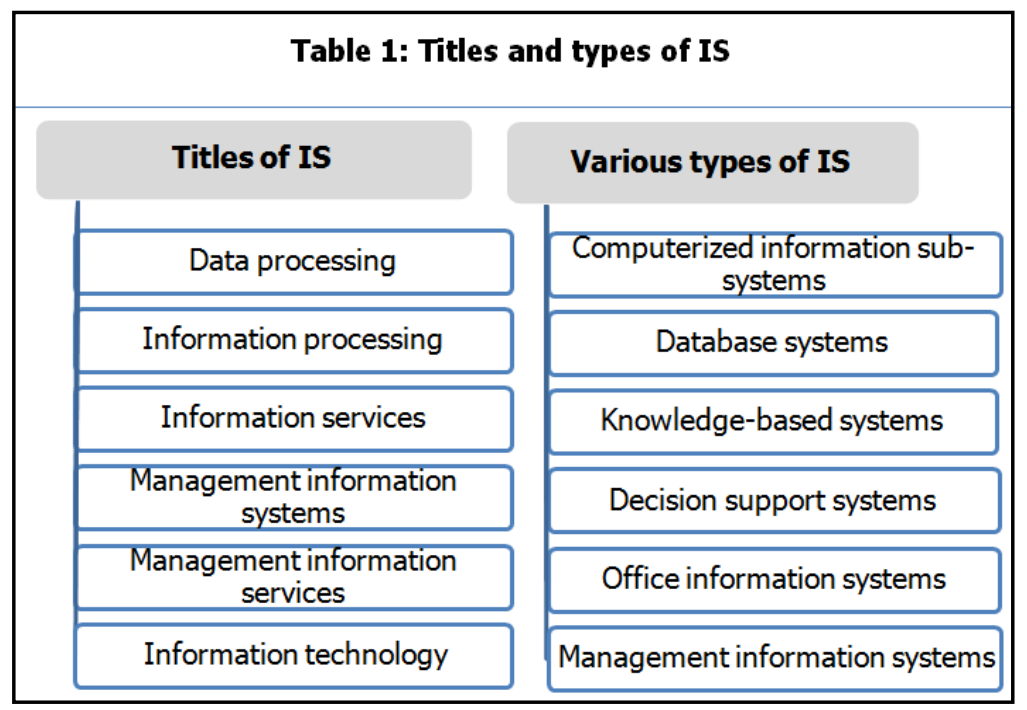

\section{Maintainability attributes of IS:-}

Maintainability attributes are a state which determines that failed system can be restored to its normal operable state within designated time by using specific procedures [18\&6], the maintainability is assumed as one of quality specifications, as the International Standards ISO/IE 9126 has specified maintainability of "IS" as one of 6 main characteristics of quality level of the software products [19], but it should holds two main components of serviceability and reparability in order to ease scheduled services and resorting services after any failure, as the 
Institute of Electrical \& Electronics Engineering (IEEE) standard glossary was defined maintainability as the ease with which a software system or a component can be modified to correct faults and improve performance which they can be reused [20]. Several other researchers have declared and resulted in their researches that the maintainability has four attributes of clearly control, dependability, used contribution, and training [8], as indicated if figure (2).

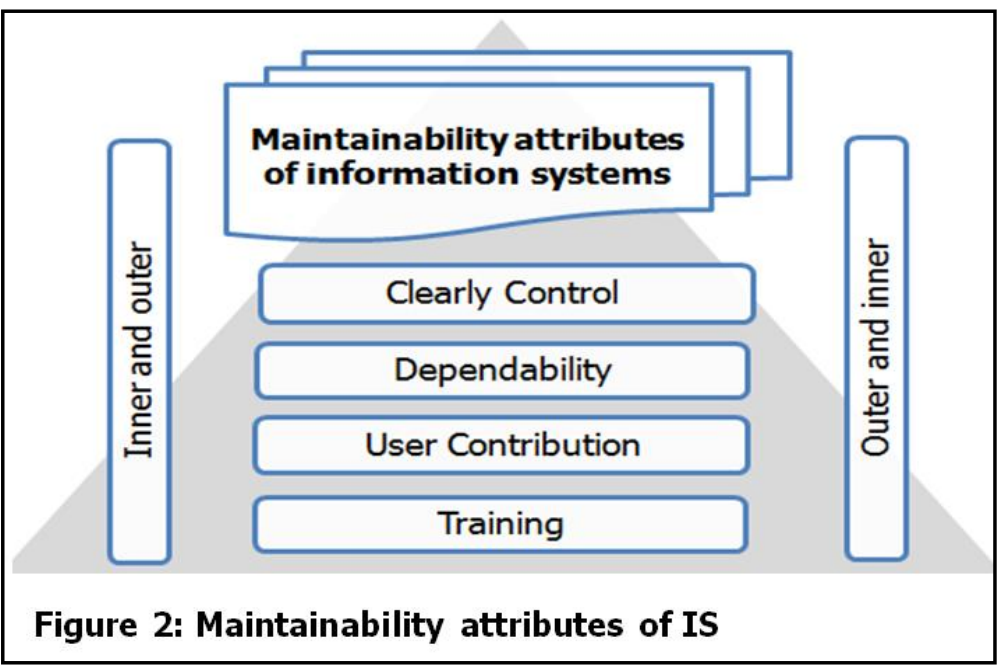

\section{Compatibility procedures:-}

Compatibility is a state in which two functioning systems are able to unify their working, and integrated in one system or a model in an organization [19], it will take many meanings according to type of integrated components, but there are some procedures in order to make compatibility, and there are series of actions to obtain required state of compatibility and they are fixed step-by-step sequence of activities to perform correctly task of compatibility [21], as affirmed in our research, the procedures are to make compatible of maintainability attributes of "IS" with elements of "TQM" in an organization.

\section{Methodology:-}

The methodology depends on 4 steps as they are assumed as compatibility procedures, to make in final a compatibility model, it comes by the method of inserting 4 main maintainability attributes of "IS" into 8 elements of "TQM", and then making integration between their functions. The methodology consists of four steps as indicated in figure (3), and after final step, the model can be achieved which comprises four compound elements as well.

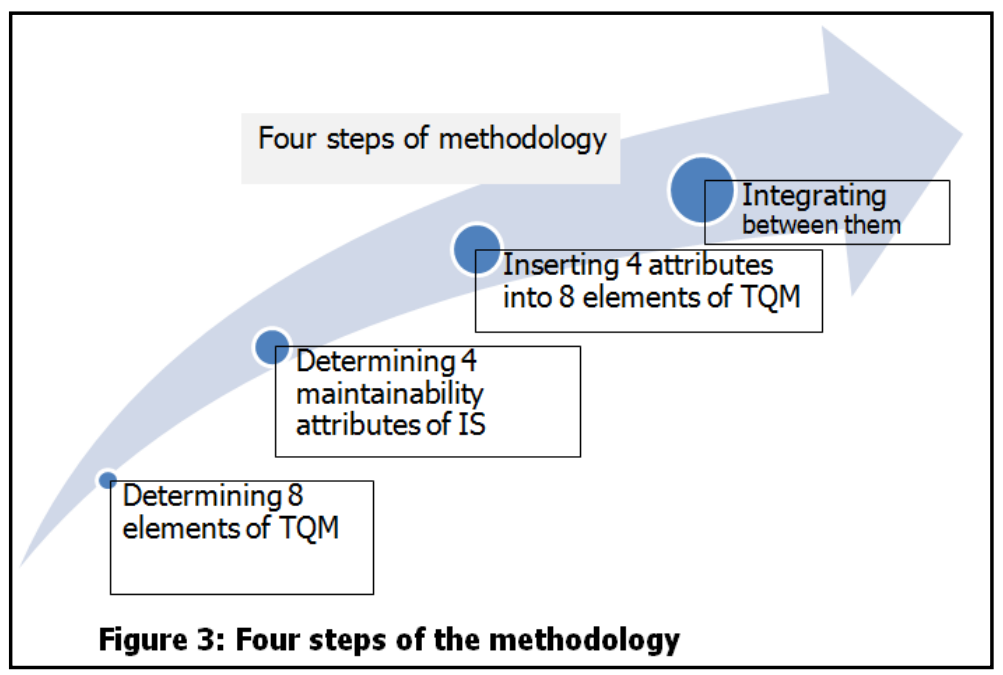




\section{Motives of TQM using and compatibility model:-}

We declare below of why we are choosing "TQM" to be a basis of compatibility, and why we make compatibility model of "IS", some reasons and motives are as follows:

- Elements of "TQM" were used for compatibility procedures and make a model, because it depends on philosophy of the "TQM" that can bring quality to seven most important factors in any organization such as: (1) customer orientation, (2) employee involvement, (3) top management commitment, (4) continuous improvement, (5) education and training, (6) quality technology, (7) quality culture [22].

- $\quad$ "TQM" was used here, because many researchers agree that "TQM" implementation will help any organization to deliver its goals and targets [23], in addition, other studies affirmed that "TQM" can be applied as a roadmap for other working systems and it improves their quality level of operations [24].

- It is too clear that the "IS" is assists organization's management to provide services to their customers, but the quality level of the provided services may be regarded as poor, therefore it is extremely needed to find a specific tool for the purpose of raising the quality level, in that case, the compatibility can be used in order to achieve increase of quality of information and knowledge outcomes [25].

- The customers need always to trust outcomes of "IS", the trusted services are required everywhere, but if used "IS" cannot give this trust as required, or it cannot able satisfy customers, in that case, it will be necessary to find a new model [26\&23]. The compatibility model can be a new model that can achieve many aims.

- As mentioned above, many studies proved that compatibility can prevent inaccurate results by "IS" outcomes, also it can reduce many risks with further success by "IS", the compatibility will perform tasks as a roadmap strategy of organization's development and the responsible management has to stress on "IS" strategy [27].

- Most tasks of the engineering will be succeeded clearly if they enriched by inserting "TQM" into their operating systems with "IS", because it enters to all parts of the engineering operations and other technical or scientific fields [7\&14].

- During portioning process of information for materials or other documents, the compatibility model can lead to obvious state, as we see in material safety data sheet MSDS as example of the technical document or bulletin that summarizes the information on health and safety available on controlled products divided items to 9 sections with 60 specific items, such as: (1) product information, (2) hazardous ingredients, (3) physical data, (4) fire or explosion hazard, (5) reactivity data, (6) toxicological properties, (7) preventive measures, (8) first aid measures, (9) preparation information [28].

- Constituting of a compatibility model 4 compound elements can be achieved in order to give results of more services such as increase stability, repair, restoring, and the continual improvement of information.

\section{Aims of the research:-}

The aims of the research can be summarized as follows:

- Review of 8 elements of "TQM", and 4 maintainability attributes of "IS"

- Review of compatibility procedures.

- Constituting a compatibility model on the basis of maintainability attributes of "IS" and key elements of "TQM".

- In order to result and gain more stability, repair, restore, and continual improvement of "IS" outcomes and higher quality of "IS" processing.

\section{Data analyzing:- TQM;-}

The implementation of "TQM" in the organizations and its integration with other systems will lead to improve efficiency of operations, more control, and minimize defects in production and services, many studies analyzed in detailed data that under eight elements of "TQM" will result improvement of the management and better control between $9-86 \%$ [14].

IS:-

If there is high quality level of four maintainability attributes, the "IS" will take more successful degree, several studies were proved that the quality factor affects software maintenance, they were analyzed that the total quality between $50-70 \%$ of "IS" is spent on software maintenance [29]. 
Analyzing the four attributes:

- Control: is assumed as central attribute for protection of information in any organization, because without control, other three attributes become inefficient in "IS" processing, therefore, the responsible management should work to increase control task at all stages, the analyzing of a study noted that the control is accountability of the responsible management to maintain better "IS" arrangement [14].

- Dependability: is assumed as ability of "IS" working to gives effective outcomes, it based on how "IS" will detect quickly those problems during the processing, because any undependable "IS" may result unexpected problems and destroyed outcomes, then this situation results untrustworthy by customers, a study analyzed that "IS" developers should concentrate on procedures to attain dependable "IS" at all stages.

- User contribution: is essential for effective information processing and its outcomes because "IS" used by individuals such as employees, customers, sellers, and other stakeholders [30], the analyzing done by a study indicated higher quality if there is encouragement to all users of "IS", because a study identified three theories in "IS" user contribution such as buying, system quality, and emergent interactions [8].

- Training: is fourth attribute and associated to all employees and users in the organization in order to enable them to deal with "IS" as much as perfect and to achieve overall goals, because a study analyzed that ongoing training is a tool of "IS" success, and analyzed that in order to improve "IS" training and maintainability in the organizations, the management would need to explore the construct of "TQM" [8].

\section{Compatibility model;-}

Compatibility model can be constituted after several procedures in which 4 attributes of "IS" inserted into elements of "TQM", the suitable functional model comes when 4 attributes integrate with 8 elements by a specific level of integration, many previous studies were outlined of three levels of integration [31], other studies tried to provide other models associated to "IS" and quality standards in an organization [32]. Here, in our compatibility model, the basic will be on 8 elements of "TQM" and can well-situated quality level result for "IS" working because they paralleled in their tasks, and it was proved that most offered successful models were paralleled in their functions [33], but all presented models were different in their contents and connection way, here, in our compatibility model, the contents consist of 4 attributes with 8 elements and connection way is inserting, it comprises 4 compound elements as indicated in figure (4) with detailed explanation as follows:

\section{First compound element:-}

This element is consists of (control) of "IS" and (ethics, integrity, and trust) of "TQM". The control inserted into each of ethics, integrity, and trust, and integrated between them. It means that each one of ethics, integrity, and trust should be controlled in "IS" processing, and this should reflects in "IS" outcomes, the control must integrate with their actions to enhance ethics, integrity, and trust of "IS", because the control gives important pillar to improve their management, and the quality measurement and control is one pillar from four pillars of constructed process management [34].

The control must imply both organizational and individual ethics, because they outline guidelines that all employees are to adhere in control of information outcomes within "IS", the quality techniques such as statistical process control SPC, variation reduction and design quality are to be used [35].

The integrity implies honesty, morals, values, and fairness, and adherence to the facts and sincerity that should be controlled in information working and be realized by all employees and customers who receive outcomes, the personnel integrity of employees will maximize organizational integrity and confidentiality [36].

The model cannot be build without trust of its functioning and full contribution of employees in "IS" working, some researches demonstrated that the trust involved into information technology of hardware or software [30], in addition it enhances quality level, more flexibility and mutual trust among members are required, because they are used in conjunction with "TQM" [37].

\section{Second compound element:-}

This element is consists of (dependability) of "IS" and (training, teamwork, and leadership) of "TQM", the dependability inserted into each of training, teamwork, and leadership, and integrated between them. It means that each one of training, teamwork, and leadership should be dependable in "IS" processing, and reflects in all "IS" outcomes, the dependability must integrate with their outcomes to enhance training, teamwork, and leadership of 
"IS", because the dependability improves them and increase the dependability of "IS" outcomes because the achievement of "TQM" would encourage these elements to be communicated towards stability other elements.

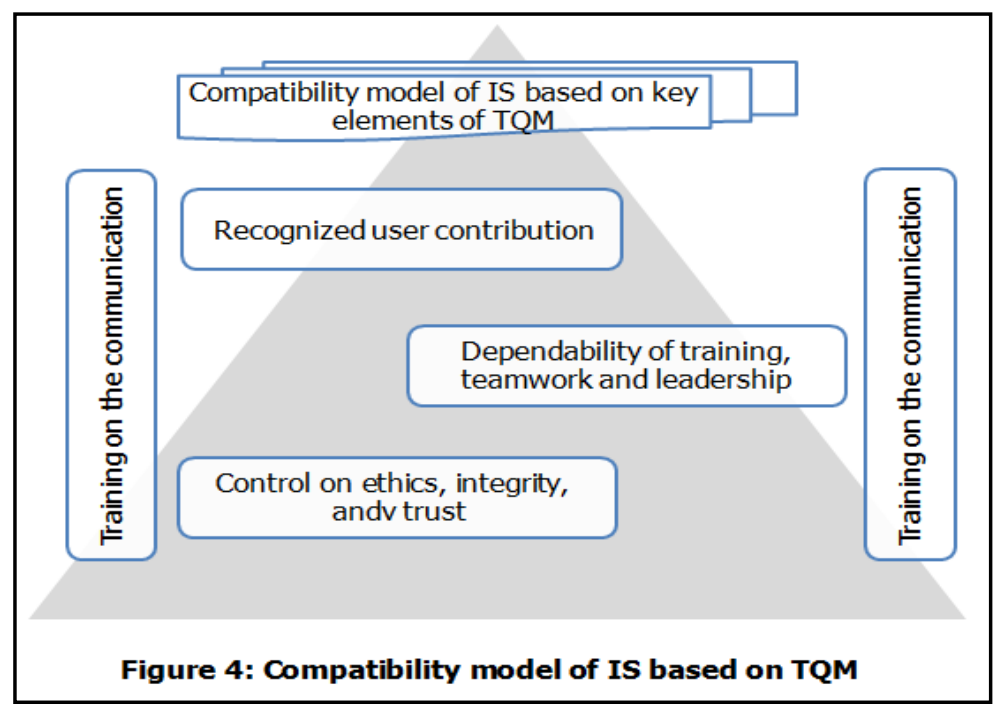

The training on "IS" processing is important but the dependable training is more significant for higher outcomes quality, and the training topic should include dependability requirement which implies required skills and ability, therefore, all employees should be trained properly and certified [38].

The teamwork is crucial element to achieve higher level of "IS" results within operations in an organization, in order to increase dependable rate of "IS" outcomes, the teamwork should have better and quicker skills in problem solving of "IS", as called by "TQM" concepts [2], and three types of teamwork can be established as:

(1) Team of "IS" improvement, in order to deal with specific problems that often occur to "IS" working, these teams are set up for a period of 3 to 12 months.

(2) Team of "IS" problem solving, in order to solve certain problems and identify true root causes of them, these teams are set up for period of 1 week to 3 months.

(3) team of "IS" natural work, it consists of small groups of skilled workers who share the same tasks and responsibilities, such as employee team and quality circle team, these teams generally meet 1 or 2 hours per week.

The leadership is the third element of this compound element, the dependability in leadership is fundamental factor to make strategy, the leadership must provide visions and missions, and make strategic directions of "IS" issues in an organization, the leadership must make "IS" strategies, "IS" philosophies, "IS" goals, and quality enhancement team [39].

Third compound element:-

This element is consists of (user contribution) of "IS" and (recognition) of "TQM". User contribution inserted into recognition and integrated between them, it means that users of "IS" working inside and outside an organization should be recognized at all stages in order to enhance "IS" processing, it can bind all locations and all users with each other in "IS" issues and increase quality of problem solving [40], hence, the recognized user contribution will be achieved with third step of the model constituting, and contribution of all users at all locations should be recognized to positive change in "IS" quality, because the simple meaning of recognition is to make good understanding between sender and receiver about processing of "IS", in this case the user contributions will regarded at higher scale, the responsible management must keep a policy to employees to have authority of contribution in order to send and receive information inside organization with outside, the recognition will be obvious and understandable messages, it should have an understandable common language for higher of communication quality with user of "IS" [41\&7]. 


\section{Fourth compound element:-}

This element is consists of (training) of "IS" and (communication) of "TQM", the training inserted into communication and integrated between them. It means the tasks of training on "IS" inside the organization should be communicated to all stages and employees in order to enhance "IS" processing. All topics and duration of "IS" training should be well communicated; this can lead to huge change in "IS" productivity and "IS" quality level. The job description falls within "IS" training, because "IS" researchers usually asked employees if they are trained in the job position they occupy and if training programs were efficient to "IS", therefore the responsible management should recognize the positions, peoples, training methods, and skill levels within work environment who influence on "IS", several researches state that each of higher quality products, improved business performance, customer satisfaction, and improved training were to have main benefits achieved by introducing "TQM" [42].

\section{Results and discussion:-}

\section{Results:-}

The research affirmed and reached to some results, as:

- There are 8 applicable and key elements of "TQM" such as: ethics, integrity, trust, training, teamwork, leadership, recognition, and communication.

- There are 4 main attributes of maintainability of "IS" such as: clearly control, dependability, user contribution, and training.

- $\quad$ Elements of "TQM" can increase quality level of the operated systems.

- Attributes of maintainability of "IS" can determine that failed system restored to its normal operable state within designated time and specific procedures.

- The compatibility is a state that can be resulted from integrating two functioning systems in any organization; also it has ability to unify their working.

- Compatibility procedures can be achieved between "TQM" and "IS" through inserting 4 attributes into 8 elements, then a compatibility model can be developed with 4 compound elements.

- There are 6 titles of "IS" processing and 6 types of "IS" working for both technical and behavioral features related to design of information outcomes in both software and hardware systems.

- Implementation of quality system will lead to:

1. Better management control by $86 \%$.

2. Supply better services for customers by $73 \%$.

3. Increase effectiveness by $69 \%$.

4. Decrease costs by $40 \%$.

5. Provide an improvement average of whole organization's tasks by $67 \%$.

- $\quad$ Inserting "IS" attributes into "TQM" elements will result:

1. Higher quality of attributes and successful "IS".

2. Better software maintenance between $50-70 \%$ of total life cycle of "IS".

- Development a model of compatibility will increase ability by an organization so it can:

1. Supply better service for the customer by $73 \%$.

2. Increase effectiveness by $69 \%$.

3. Decrease costs by $40 \%$.

4. Increase employee motivation by $50 \%$.

\section{Discussion:-}

"TQM" has eight key elements by which quality system can be implemented and provide customers with products and services that satisfy their needs, also it strives to enhance quality level and tries to avoid defects in any operation such as "IS".

"IS" has tools to design information and how implementing them in an organization, also it prepares technologies to support this design, but "IS" can give more accurate and durable results when inserted into quality system, hence, more successful "IS" working can be achieved, when four main attributes inserted into eight elements of "TQM" and integrated, because it conducts scheduled services, resorts information after failure, modifies "IS" components, and corrects outcomes, this new situation is regarded as compatibility. The compatibility procedures consist of 4 main steps, because with them, the compatibility state can be achieved, and "TQM" can imply "IS" objectives, in addition, these steps assist to develop a model of compatibility with four compound elements as well. 
Therefore, the developed model consists of four compound elements which lead to more successful and higher quality of "IS" working, and it can increase the stability, repair, restore, and continual improvement of information, also the outcome of "IS" would be in higher level and enhanced processing in each compound element works.

In first compound element, the ethics outline guidelines because all employees have to adhere control of information outcomes, the integrity implies morals and values, because all facts and sincerity have to be controlled and realized by both employees and customers who give and receive "IS" outcomes, the trust is fixed among members because they are used required mutual trust but in conjunction with "TQM".

In second compound element, the training should be dependable because it assumed as significant for higher quality outcomes of "IS", also the dependability teamwork can achieve higher level of "IS" results in an organization, higher rate of dependability gives better skills and quicker in problem solving, the dependability of leadership is crucial in "IS" working because it constitutes visions and missions of the organization. The recognized user contribution is required because it means the understanding of "IS" processing between sender and receiver; also user contribution of recognition is necessary because the recognition will enhance user contribution towards high grade of "IS" working.

In fourth compound element, training of communication is regarded as vital task, because it can lead to huge change in "IS" productivity with better quality specifications.

\section{Conclusions and recommendations:- Conclusions;-}

Total quality management "TQM" is an arranged management of quality in an organization; it deals with customer requirements. Information System "IS" is a study of how such system stores, processes, manages and makes information available for use. The compatibility is a state in which both two systems able to integrate their processes and can work together, it assists organizations to design and implement information with high level of quality and prepare technologies that support them, in which it can give more accurate results.

The compatibility procedures depend on a methodology consists of 4 steps in which 4 maintainability attributes (clearly control, dependability, user contribution, and training) of "IS" be inserted into 8 elements (ethics, integrity, trust, training, teamwork, leadership, recognition, and communication) of "TQM". A developed model cab be resulted including 4 compound elements, the first is consists of ethics, integrity and trust, they are should be controlled in "IS" processing, second is consists of training, teamwork, and leadership, they are should be implemented in full range of dependability as foundation of "IS", third is consists of communication, it should be enter into all parts of the developed model to bind all locations with each other in "IS" working and to increase quality of problem solving between sender and receiver, and user contribution be in higher grade, and fourth compound element is consists of recognition, the training should be evaluated into the recognition state, it can be achieved with recognized method and job description, it was enhanced by International Standards ISO/IE 9126 that has specified maintainability of "IS" as one of 6 main characteristics of quality level of the software products.

"TQM" is used for this compatibility, because it is a management approach that strives to provide customers with products and services that satisfy their needs and it enhances quality level, and tries also, to avoid wastes and defects in any operations, and it assists maintainability attributes that failed systems can be restored to its normal operable state within designated time, and be successful task when conducting scheduled servicing, resorting service after a failure, modify components, and fault correct. Nowadays "IS" will face many problems and difficulties to repair or restore information and knowledge of operations in the organizations, the organizations need severe solution to strengthen four maintainability conditions of "IS", and "TQM" will imply this objective, because it is a tool for improvement and assure availability of information with higher quality level.

\section{Recommendations:-}

After results and discussion, we recommend:

- The elements of the "TQM" should be integrated in "IS" processing because they can give both user satisfaction and customer satisfaction as receivers of "IS" outcomes, and they present quality specifications to "IS" working and programs. 
- To insert 4 maintainability attributes into 8 elements of "TQM", because many studies analyzed in details that they can result management improvement to higher ratio and this will produce succesful "IS" results in the organizations.

- To develop compatibility state between "IS" and "TQM", because it enhances working through philosophy of "TQM", and because it can bring quality to 7 important core factors in an organization.

- To constitute a model of compatibility with four compound elements, because they outline guidelines for successful 4 maintainability attributes of "IS" with 8 elements of "TQM".

The recommendations based on the development of a compatibility model, because it can give more benefits and quality to "IS" outcomes, also the findings were indicated that the model is necessary to prevent inaccurate determination of project, reduce risks, and to encourage successful system, other advantage is that the model can perform these objectives as a roadmap strategy in the organizations.

\section{References:-}

1. ASQ (American Society for Quality), Available in http://asq.org/glossary/q.html/ about-quality, total quality management.

2. Irikefe. Urhuogo, and Harich. C. Chandan, 2012, "Information Systems Effectiveness: the Application of Corporate Social Responsibility Policy and Total Quality Management Model", Journal of Business Studies Quarterly, Vol. 4, No. 1, ISSN: 2152-1034, Page 182-190.

3. Steven Alter, Oct. 2008, "Defining Information Systems as Work Systems: Implications for the IS Field", University of San Francisco, European Journal of Information Systems, Vol. 17, No. 5, pp. 448-469, page 3-4.

4. https://en.wikipedia.org/wiki/Information_system

5. http://www.britannica.com/topic/information-system

6. http://www.businessdictionary.com/definition/compatibility, maintainability

7. J. Milosan, Feb. 2014, "Studies about the Key Elements of Total Quality Management", European Scientific Journal, Special edition, Vol. 3, ISSN: 1857 - 7881- Print, e - ISSN 1857- 7431, Page 58-60.

8. K. N. Shen, M. Khalifa, and A. Almulla, 2013, When Users are Professionals: Effective User Participation for Information Systems Assimilation, Thirty Fourth International Conference on Information Systems, University of Wollongong in Dubai, Page 1-14.

9. Sami Nizar Khasawneh, Adel Odeh AL-Hashem, Waleed Kalf Ali Al-Zoubi, July 2012, "Application of Total Quality Management System (TQMS) and its Impact on Competition Policy in Industrial Plants: An Empirical Asudy on Facilities of Industrial Sector in Jordan", Far East Journal of Psychlogy and Business, Vol. 8, No. 1, Page 6.

10. I. Urhuogo, V. Vann, and H. C. Chandan, 2012, Information Systems Maintenance: the Application of Total Quality Management Construct, Journal of Business Studies Quarterly, Vol. 3, No. 3, ISSN: 2152-1034, Page 115.

11. R. R. Lakhe, and R. P. Mohanty, 1994, "Total Quality Management Concepts, Evolution and Acceptability in Developing Economies, International Journal of Quality \& Reliability Management", Vol. 11, No. 9, 0265671X, MCB University Press, Page 9-12.

12. S. M. Yusof, and E. Aspinwall, 2000, "Total Quality Management Implementation Framework: Comparison and Review", Total Quality Management, Vol. 11, No. 3, ISSN 0954-4127 print/ISSN 1360-0613, 2000 Taylor \& Francis Ltd., Page 281-282.

13. N. Gherbal, A. Shibani, M. Saidani, and A. Sagoo, 2012, Critical Success Factors of Implementing Total Quality Management in Libyan Organizations, Proceedings of the 2012 International Conference on Industrial Engineering and Operations Management Istanbul, Turkey, July 3- 6, 2012, Page 80-89.

14. J. Ruzevicius, R. Adomaitiene, and J. Sirvidaite, March 2004, "Motivation and Efficiency of Quality Management Systems Implementation: A Study of Lithuanian Organizations", Total Quality Management, Vol. 15, No. 2, Taylor \& Francis Ltd., Page 174-181.

15. BCS Definition from PC Magazine Encyclopedia, www.pcmag.com/encyclopedia/term

16. E. D. Falkenberg, W. Hesse, and P. Lindgreen, 1998, A Framework of Information System Concepts, The FRISCO Report, IFIP, ISBN 3-901882-01-4, Department of Computer Science, University of Leiden, The Netherlands, Page 1-73.

17. https://en.wikipedia.org/wiki/Information_system

18. A. Aljaafreh, and A. Al-Ani, 2014, Conceptualizing Initial Trust in Internet Banking Services: A Pilot Study, From: Information Systems Development: Transforming Organizations and Society through Information 
Systems- Proceedings of the 23rd International Conference on Information Systems Development (ISD2014 Croatia), Varazdin, Croatia, ISBN 978-953-6071-43-2, September 2-4, 2014, Page 52.

19. A. Ebrahimi, October 2010, Effect Analysis of Reliability, Availability, Maintainability and Safety (RAMS ) Parameters in Design and Operation of Dynamic Positioning (DP) Systems in Floating Offshore Structures, Master's Degree Project, KTH School of Industrial Engineering, Stockholm, Royal Institute of Technology, Page 71.

20. H. P. Barringer, Feb. 18, 1997, Availability, Reliability, Maintainability, and Capability, Barringer \& Associates, Inc., Humble, TX, Triplex Chapter of the Vibrations Institute Hilton Hotel Beaumont, Texas, available in http://www.barringer1.com., Page 7.

21. R. Al-Jalahma, and D. Gallear, 2010, Exploring the Relationships between Core Elements of TQM Implementation, From: European, Mediterranean \& Middle Eastern Conference on Information Systems, (EMCIS), Abu Dhabi, UAE, April 12-13-2010, Page 1.

22. P. L. Chang, and P. D. Shen, 1997, "A Conceptual Framework for Managing End-User Computing by the Total Quality Management Strategy, Total Quality Management, Vol. 8, No. 1, Page 94-95.

23. A. Kappos, and S. Rivard, Review: Cultural Interpretations from Multiple Perspectives: A Three-Perspective Theory of Culture, Information Systems and the Development and Use Processes, HEC Montreal, Mai 2007, ISSN 1702-238X, Page 3-15.

24. D. T. Hoang, B. Igel, and T. Laosirihongthong, Sep. 2010, "Total Quality Management (TQM) Strategy and Organizational Characteristics: Evidence from a Recent WTO Member", Total Quality Management, , Vol. 21, No. 9, Taylor \& Francis Group, Page 933-955.

25. ISO/IEC FDIS 9126-1: 2000-03-20 - Information Technology- Software Product Quality - Part 1: Quality Model, ISO copyright office, Case postale 56. CH-1211 Geneva 20.

26. Z. Rosko, 2014, Predicting the changeability of software product lines for business application, From: Information Systems Development: Transforming Organizations and Society through Information Systems, Proceedings of the 23rd International Conference on Information Systems Development (ISD2014 Croatia), Varazdin, Croatia, ISBN 978-953-6071-43-2, Sep. 2-4, 2014, Page 318.

27. B. J. da Cunha, and P. Rupino, 2014, Towards a Business Process Quality Culture: from High-Level Guidelines to Grassroots Actions: From Information Systems Development: Transforming Organizations and Society through Information Systems- Proceedings of the 23rd International Conference on Information Systems Development (ISD2014 Croatia), Varazdin, Croatia, ISBN 978-953-6071-43-2, Sep. 2-4, 2014, Page 7.

28. Ontario, August, 2008, Workplace Hazardous Materials Information System (WHMIS): a Guide to the Legislation, ISBN (HTML): 978-1- 4249- 6996-8. Queens's Printer for Ontario, Pages 15-16 and 89-91.

29. A. Hincheeranan, W. Rivepiboon, July 2012, "A Maintainability Estimation Model and Tool", International Journal of Computer and Communication Engineering, Vol. 1, No. 2, Page 143.

30. J. He, W. R. King, 2008, "The Role of User Participation in Information Systems Development: Implications from a Meta-Analysis", Journal of Management Information Systems, M.E. Sharpe, Inc., Vol. 25, No. 1, Page 301-331.

31. H. Kaur, and S. Singh, 2012, "Maintenance Model for Open Source Object Oriented Software", International Journal on Advanced Computer Theory and Engineering (IJACTE), Vol. 1, Issue. 1, Print ISSN: 2319- 2526, Page 59.

32. A. Sidorova, N. Evangelopoulos, J. S. Valacich, and T. Ramakrishnan, 2008, "Uncovering the Intellectual Core of the Information Systems Discipline, MIS Quarterly, Vol. 32, No. 3, Page A1-A20.

33. R. Ohl, and J. Gammack, 2004, "Integrating an Internet Management System into a Virtual Private Network, Journal of Electronic Commerce Research, Vol. 5, No. 4, Page 258-267.

34. D. Leonard, and R. McAdam, 2002, "Developing Strategic Quality Management a Research Agenda", Total Quality Management, Vol. 13, No. 4, ISSN 0954-4127, print ISSN 1360-0613, Taylor \& Francis Ltd., Page 507-522.

35. M. Ul Hassan, M. S. Nawaz, S. Shaukat, and S. Hassan, 2014, An Empirical Assessment of TQM Dimensions and their Relationship with Firm Performance: Evidence from the Textile Sector of Pakistan, World Applied Sciences Journal 30 (6): 696-705, IDOSI Publications, ISSN 1818-4952, Page 697.

36. D. Gurpreet, and T. Gholamreza, 2006, "Value-Focused Assessment of Information System Security in Organizations", Information Systems Journal, Vol. 16, Blackwell publishing Ltd, Page 293-314.

37. A. K. Mohammad, and A. Al Bakri, 2013, "Evaluation Tools of Total Quality Management in Business Organizations", European Journal of Business and Management, Vol.5, No. 6, ISSN 2222-1905, Paper ISSN 2222-2839, Page 43. 
38. S. Pankaj, J. Naman, and P. Kunal, June 2013, "TQM: Implementation, Scope and Myths - A Review", Research Journal of Engineering Sciences, Vol. 2(6), ISSN 2278- 9472, Page 40-41.

39. N. Callaos, and B. Callaos, 2002, "Toward a Systemic Notion of Information: Practical Consequences, Informing Science, Volume 5, No 1, Page 9.

40. H. Barki, and J. Hartwick, March 1994, "Measuring User Participation, User Involvement, and User Attitude", MIS Quarterly, Vol. 18, No. 1, Page 59-82.

41. J. Hartwick, and H. Barki, April 1994, "Explaining the Role of User Participation in Information System Use", Management Science, Vol. 40, No. 4, Page 440-465.

42. Y. A. Chauhan, P. M. George, and H. J. Jani, March 2014, "Perceptions of SMEs (Manufacturing Firms) Towards the Key Elements of TQM", International Journal of Research in Engineering and Technology IJRET, Vol. 3, Issue 3, eISSN: 2319-1163, pISSN: 2321-7308, Available in www.ijret.org., Page 540-545. 